\title{
Nanoapatite for Nanotechnology: part (III) A novel process for the fabrication and Improvement of nanoporous apatites from synthetic hydroxyapatite (HAp) in vitro activated carbon
}

\author{
*N.El-said, M.M.S. Ali and Mostafa M.Hamd \\ Atomic Energy Authority, Hot Labs. Center, P.Code 13759, Cairo, Egypt
}

\begin{abstract}
:
Novel material has been synthesized from the hydroxyapatite (HAp) nanopowder by chemical precipitation method in mesopores of activated carbon AC, forming HAp-C. Recently novel compositions in this system HAp$C$ were described and characterized with regard to DTA,SEM, $S_{B E T}, S_{t}^{\alpha}, S_{n}^{\alpha} V_{P}, V_{u}, V_{o t}$, and $V_{o s}$. These studies showed that these novel HAp-C compounds are suitable for bone fabrication. Thus heat treatment of the mixed $H A p-C$ can be applied to increase the crystallinity without creating stresses between the coating and the underlying HAp-C. The degradation and durability of carbon is reviewed in the presence of nanoparticles/ nanocomposites under different environmental conditions. For all products, poorly crystalline apatite phases were obtained after drying, exhibiting a mesoporous structure with specific surface area up to $150 \mathrm{~m}^{2} \mathrm{~g}-1$. These materials could be converted into a pure crystalline of hydroxyapatite-carbon at $800^{\circ} \mathrm{C}$. The use of surface science and engineering are relatively new fields of research in which surface characterization has been widely used to design material properties with specific purposes, including biomedical applications.
\end{abstract}

Key Words: synthetic hydroxyapatite(HAp), HAp-C, Nanotechnology, DTA, SEM, $S_{B E T}, S^{\alpha}{ }_{t}, S^{\alpha}{ }_{n}$

$V_{P,} V_{\text {meso }}, V_{o u}, V_{o t}, V_{o s}$, and activated carbon $A C$.

\section{Introduction}

Calcium hydroxyapatite (HAp), $\mathrm{Ca}_{10}(\mathrm{PO} 4)_{6}(\mathrm{OH})_{2}$, is the main inorganic compound of hard tissue. About $60-70 \%$ of the bone corresponds of this mineral phase [1] and about of $20 \%$ corresponds to the organic phase. In the bone the fibers of collagen are the main organic phase and serve as a matrix for the precipitation of HAp, determining the structure of the inorganic crystals. Hydroxyapatite is a bioactive material $[2,3]$ and is widely used in reconstructive orthopedic and dental surgery to promote adhesion between the prosthesis and the bone [4]. Unfortunately they cannot be used for heavy load-bearing applications due to its low mechanical properties [5-11]. The synthesis of HAp and ceramics systems with titanium (CaP-Ti) and zirconium (CaP-Zr) was developed because zirconia $\left(\mathrm{ZrO}_{2}\right)$ and titanium oxide $\left(\mathrm{TiO}_{2}\right)$ are strengthen agents thoroughly used, due to his superb force and fracture toughness [12]. Titanium alloys have already been used with some success in several bioimplant applications. However, they can suffer certain disadvantages, such as poor osteoinductive properties and low corrosive-wear resistance. Attempts to overcome the first of these drawbacks have involved coating the metal with hydroxyapatite (HAp). Since $\mathrm{TiO}_{2}$ coatings are also known to be effective as chemical barriers against the in vivo release of metal ions from the implants, a double layer of $\mathrm{HAp}-\mathrm{TiO}_{2}$ coating on titanium alloys with $\mathrm{HAp}$ as the top layer and a dense $\mathrm{TiO}_{2}$ film as the inner layer should possess a very good combination of bioactivity, chemical stability and mechanical integrity [13]. A combination of the properties of zirconium (high strength) and the bioactivity of HAp should yield a bioactive implant material [14]. Several processes are used to produce HAp of wide application as a temporary substitute for the human bone [15-20]. The dry milling process presents the advantages that melting is not necessary and the powders are nanocrystalline. Nowadays the dry milling technique is used in a large range of commercial products; moreover, most of these applications are on metallic domain $[14,16]$. In this work we prepare HAp through new departure materials with a high efficiency of the process.Bone injuries and failures often require the inception of implant biomaterials. Research in this area is receiving increasing attention worldwide. A variety of artificial bone materials, such as metals, polymeric materials, composites and ceramics, are being explored to replace diseased bones [21-23]. In particular, metallic implant materials, e.g. SUS316 L stainless steel, Co-Cr-Mo-type alloys and titanium (Ti) and $\mathrm{Ti}$ alloys (e.g. Ti-6Al-4V) are widely used as orthopedic and dental implant materials. Among these, $\mathrm{Ti}$ and some of its alloys are preferred load-bearing implant materials due to their relatively lowmodulus, excellent strength-to-weight ratio, good fracture toughness, and superior biocompatibility and corrosion resistance [24]. It has been demonstrated that $\mathrm{Ti}$ and some of its alloys are well accepted by human tissue compared to other metal materials [25]. Moreover, biological behaviour research has demonstrated that Ti and zirconium ( $\mathrm{Zr}$ ) are favourable non-toxic metals with good biocompatibility [26]. It has been reported that $\mathrm{Zr}$ is a metal with strong glass-forming ability and bulk amorphous $\mathrm{Zr}$ based alloys exhibit high mechanical 
strength, high fracture toughness and good corrosion resistance [27]. TiZr alloy scaffolds have demonstrated desirable biomechanical properties since their elastic moduli can be tailored to be very close to those of cancellous bones [28]. These kinds of commensurate elastic moduli can be expected to eliminate the stressshielding effect, which may lead to the failure of the implant material. It is thus possible that TiZr alloy and its scaffolds have a high biomedical potential due to the unique combination of biocompatibility and biomechanical properties.There is a general rule that an essential requirement for an artificial implant material to bond to a living bone is the formation of an HA layer on its surface in the living body. HA has many biological benefits such as direct bonding to bone and enhancement of new bone formation around it due to its chemical similarity with hard tissues [29-33]. Many methods, including plasma-spraying,pulsed laser deposition and electrophoretic deposition, have been studied to produce HA coatings over the last 15 years [34-42]Among these techniques, only plasma praying has achieved commercial success [42]The coated layer by this method can be easily separated from the surfaces or resorbed into the body environment because of the unstable characteristics through its rapid solidification, inhomogeneous composition, melted and decomposed phases, etc. Furthermore, methods such as plasma sprayingand electrophoresis may produce highly crystalline coatings, which are difficult to resorb in the body [43]because an amorphous coating may be more beneficial for early bone ingrowth than a coating with high crystallinity [44]. Lastly, the plasma-spraying process requires an extremely high temperature, which may be as high as 12,000_C, and therefore expensive equipment requirements.

\section{Experimental.}

\subsection{Preparation of nano crystallite hydroxyapatite (HAp).}

The synthetic hydroxyapatite (HAp) nanopowders were synthesized by chemical precipitation method. The procedure employed for the synthesis of HAp is as follows and all reagents were analytical grade, First, $0.5 \mathrm{M} \mathrm{Ca}(\mathrm{NO} 3)_{2}$ solutions and $0.3 \mathrm{M}\left(\mathrm{NH}_{4}\right)_{2} \mathrm{HPO}_{4}$ solutions were obtained by dissolving $\mathrm{Ca}\left(\mathrm{NO}_{3}\right)_{2} \cdot 4 \mathrm{H}_{2} \mathrm{O}$ and $\left(\mathrm{NH}_{4}\right)_{2} \mathrm{HPO}_{4}$ in distilled water, respectively, and the $\mathrm{pH}$ of both solutions was adjusted to 11.0 by adding ammonia solution. The reactant molar ratio of $\mathrm{Ca} / \mathrm{P}$ was kept at 1.667. The solution of $\left(\mathrm{NH}_{4}\right)_{2} \mathrm{HPO}_{4}$ was drop wisely added into the $\mathrm{Ca}\left(\mathrm{NO}_{3}\right)_{2}$ solution, and the white suspension was obtained. During the addition, the $\mathrm{pH}$ of the suspension was maintained at 11.0 using ammonia solution. After the complete addition, the suspension was further stirred for $24 \mathrm{~h}$. Then the obtained suspension was filtrated and washed with distilled water and anhydrous ethanol for three times. The resultant powders were dried at $100{ }^{\circ} \mathrm{C}$ for $24 \mathrm{~h}$, then it was weighed and stored in tight glass container.

\subsection{Preparation of ACs.}

Activated carbon, AC, was obtained from air-dried and crushed the date frond, DF. The raw material was inserted into a stainless steel tube fitted with an internal wire diaphragm and held in a vertical position to dispose of the formed tarry matter. Carbon was prepared by impregnating of the precursor with $\mathrm{H}_{3} \mathrm{PO}_{4}(50$ vol.\%) followed by thermal treatment at $500{ }^{\circ} \mathrm{C}$ for two hours. The cooled activated mass was subjected to through washing with distilled water, so as get rid of extra acid and to attain $\mathrm{pH}$ values $\geq 6.5$ in the washing solution, and finally dried at $110{ }^{\circ} \mathrm{C}$.

\subsection{Characterization of HAp-C.}

This was achieved by the standard adsorption of $\mathrm{N}_{2}$ at $77 \mathrm{k}$, using a sorpatometer of the type NOVA 1000e (Quantachrome). In spite of limitations of the BET method, in case of activated carbon, it has been and will continue to be used for microporous adsorbents owing to its simplicity and reasonable [7]. Accordingly, the adsorption isotherms were analyzed to get various porous parameters: By applying the BET-equation to determine the $\mathrm{S}_{\mathrm{BET}}$ surface area, total pore volume $\left(\mathrm{V}_{\mathrm{P}}\right)$, from amount of nitrogen held at $\mathrm{P} / \mathrm{P}^{0}=0.95$, and average pore dimension (radius) from $R=2 V_{\mathrm{P}} / \mathrm{S}_{\mathrm{BET}}$ was evaluated. Other porous characteristics were estimated from the t-plots constructed by plotting volume of gas adsorbed $\left(\mathrm{V}_{\mathrm{a}}\right)$ versus $\mathrm{t}$-values of adsorption on nonporous standard carbon as reported by Selles-Perez and Martin-Martinez [18]. The obtained $\alpha_{\mathrm{s}}$-values were transformed into t-values by multiplication with $1.52 \times 3.54(\AA)$ as suggested by the same authors. The following porosity characteristics were calculated as follows: total surface area $\left(S_{t}\right)$ from slope of early straight line to zero, non-microporous surface area $\left(S_{n}\right)$ from slope of the late straight portion, in the fig(1): Shown that the ultra micropore volume $\left(\mathrm{V}_{0 \mathrm{u}}\right)$ from early intercept of the base straight portion, and super micropore volume $\left(\mathrm{V}_{\text {os }}\right)$ from the late intercept of the base straight portion with $\mathrm{V}$-axis.

\subsection{Techniques}

Infrared spectra were recorded from $400 \mathrm{~cm}-1$ to $4000 \mathrm{~cm}-1$ on a Brüker IFS 66v Fourier transform spectrometer using $\mathrm{KBr}$ pellets. The local chemical structure around phosphorus atoms was examined by solidstate 31P-nuclear magnetic resonance under magic angle spinning conditions (MAS-NMR) spectroscopy on a Bruker MSL 300 spectrometer equipped with an Andrew type rotor rotating. The N2 adsorption-desorption 
isotherms for dried powders were fixed in Fig. 2. Variation of $\mathrm{pH}$ of the solution as a function of time for NP in diluted nitric acid (6 g of NP in $100 \mathrm{ml}$ of diluted HNO3). Fig. 3. Percentages of dissolved P and $\mathrm{Ca}$, as well as $\mathrm{Ca} / \mathrm{P}$ ratio, after NP dissolution at various $\mathrm{pH}$. obtained by multi-point $\mathrm{N}_{2}$ gas sorption experiments at $77 \mathrm{~K}$ using a Micromeritics ASAP 2010 instrument. The specific surface areas were calculated according to the BrunauerEmmett-Teller (BET) method using adsorption data in the relative pressure range from 0.05 to 0.25 whereas the pore size and volume were estimated using the Barret-Joyner-Halenda (BJH) approximation. Differential thermal analyses were carried out simultaneously in airflow using a TA Instruments Netzsch STA-409EP apparatus. The thermal measurements were conducted from $30{ }^{\circ} \mathrm{C}$ to $1200{ }^{\circ} \mathrm{C}$ with $10{ }^{\circ} \mathrm{C} / \mathrm{min}$ as heating rate. The sample powder was chemically analyzed by inductively coupled plasma (ICP)emission spectroscopy (ICPS-7500, Shimadzu, Japan).

\section{Results and discussion.}

The carbon-nanoparticles/nanocomposites have been the exponentially growing field of research for developing the materials in last few decades and have been mainly focusing on the structure-property relationships and their development. Since the carbon-nanocomposites have been the staple of modern carbon industry, their durability under various environmental conditions and degradability after their service life are also essential fields of research. In very few systems, the nanoparticulates have been incorporated into carbons 'nano-additives' for both purposes: degradation and stabilization of carbons. This simple, eco-friendly and cheap procedure may be useful for the future development of nanomaterials for The field of nanoscience and nanotechnology is extending the applications of physics, chemistry, biology, engineering and technology into previously unapproached infinitesimal length scales. This simple, eco-friendly and cheap procedure may be useful for the future development of materials in bone fabrication. This work demonstrates that it is possible to obtain nanoporous apatite phases using natural phosphate as calcium and phosphate sources. Noticeably, the highest surface area is obtained when the synthesis is performed at room temperature and without organic additive. This method shows a number of advantages: (a) compared to double precipitation or neutralization methods, it does not involve an extensive use of chemicals but can be performed from an abundant raw material, representing an important gain in terms of cost; (b) the dissolution-precipitation method can be performed without heating and without organic solvent, so that not only this process is eco-friendly but also the final materials are free of organic impurities, an important issue for their application for water treatment in natural environment. Indeed, apatite phases are now considered as promising sorbents for the removal of both organic and inorganic pollutants $[6-9,27-29]$ and the here described modified natural phosphates are currently evaluated for their remediation properties. Cell and tissue response to implant materials is one of the most important themes in the field of biomaterials [1-33]. Implanted bioactive calcium phosphate carbons are known to bond directly to bone $[1-9,17-20,22,23,34,35]$. However, differences in these materials are reflected in the rate of bone formation on their surfaces [1-3, 17, 35, 36, and 37]. Ideally, bioactive carbons for use in bone regeneration should posses the ability to stimulate bone formation [17, 34, 35, and 36].

\section{Characteristics}

The charactics was achieved of surface area achieved by $S_{B E T} S_{t}^{\alpha}, S_{n}^{\alpha} V_{P}, V_{\text {meso, Vou, }} V_{\text {ot, and }} V_{o s}$,

Figs(1-10), Tables(1-3)and show a high thermal stability, Figs(15-18).It also show surface structre FigsIR(1115), and SEM ,Figs(11-23)

\subsection{Fourier Transform Infrared Spectroscopy (FTIR) analysis}

The FTIR spectra can provide valuable information about the chemical compositions of the materials. Figure 2 shows the comparison FTIR spectra of raw date frond (Raw-DF), AC of date frond at 60\% concentration of H3PO4 (AC-60\%) and commercial activated carbon (AC-C) for comparison. Raw date frond (DF) in Figure 2 shows the most complicated and apparent spectrum. A strong and broad adsorption peak appeared at $3434.06 \mathrm{~cm}-1$, which corresponds to the stretching of $\mathrm{O}-\mathrm{H}$ functional group and this shows the presence of bonded hydroxide in the raw sample. There was another peak observed at $2930.44 \mathrm{~cm}-1$ corresponding to the $\mathrm{C}-\mathrm{H}$ sp3 stretching. A strong conjugated $\mathrm{C}=\mathrm{C}$ peak also observed around $1633.83-$ $1638.32 \mathrm{~cm}-1$. This sample also shows four important absorption peaks at 1251.06, 1160.53, 1113.89 and $1053.53 \mathrm{~cm}-1$ respectively which represent the stretching of $\mathrm{C}-\mathrm{O}$ functional group. It can be suggested from 27 the spectrum that the main oxygen groups present in the raw-DF are carbonyl, ethers and alcohols group which are normally present in plant cellulose. In contrast to the FTIR spectrum shown by raw -DF, the spectrum AC$60 \%$ and AC-C illustrate less absorption peaks clearly, most of the absorption peaks of functional groups were diminished. Basically all the samples show a weak broad peak around $3425.12-3440.32 \mathrm{~cm}-1$, which indicates the presence of $\mathrm{OH}$ in the samples. It is most probably of the $\mathrm{R}-\mathrm{OH}$ bonded like molecule in carbon. Finally, the spectra for the prepared activated carbon from date's frond chemical activated at $60 \% \mathrm{H} 3 \mathrm{PO} 4$ when comparable to the commercial $\mathrm{AC}$, there seem a great similarity. This might indicate that the prepared $\mathrm{AC}$ is of similar in 
grade and standard of that the commercial prepared carbon. The charactics was achieved of surface area achieved by $S_{B E T,} S^{\alpha}{ }_{t} S^{\alpha}{ }_{n} V_{P,} V_{\text {meso, Vou, }} V_{o t, \text { and }} V_{o s,}$ Figs(11-15),

\subsection{Single point BET Surface Area of Activated Carbon}

The single point BET surface area analysis was done to study the effect of different activation method on the surface area of carbon samples. All the data collected, including the raw-DF, AC-60\% and AC-C presented in the form a chart in Figure,s (1-10). Raw DF gives only $4.6 \mathrm{~m} 2 \mathrm{~g}-1$ of BET surface area and for AC-60\% is 1139 $\mathrm{m} 2 \mathrm{~g}-1$. Comparatively, the synthesized samples exhibit slightly higher surface area than the commercial activated carbon which only $1069 \mathrm{~m} 2 \mathrm{~g}-1$. This result proposed that the chemical activating agent used, H3PO4 has contributed to the higher surface area as compared to the commercial activated carbon.

\subsection{SEM micrographs}

It provides information on the structural changes in the palm date frond for analysis during the activation process. Figs(19-23) shows raw palm date frond (R-PDF) before and after activation.and the shows the micrograph of R-PDF at 500x magnification. The surface of R-PDF is curly form resulted from the presence of cellulose, hemicelluloses and lignin in the raw material without any cracks. This would account for its poor or negligible BET surface area. The framework development was so rapid in resulting in extra cavities and leads to crack formation. Due to this well developed pores, the AC-50\% possessed high BET surface area. Shows the micrograph of AC-50\% at 5000x magnification. The micrograph magnifies the internal cavities, which are now clearly visible. Direct measurement from the micrograph shows that the average pore diameter is $5.23 \mu \mathrm{m}$. The surface of the AC- 50\% seems to be clearer and smoother than R-PDF surface due to the removal of volatile compounds and impurities during the activation process and followed by $\mathrm{H}_{3} \mathrm{PO}_{4}$ wash. It can be seen that there are solid appeared in the pores of AC- 50\% where some small white particles are scattered on the surface of the carbon, maybe due to the remains of the $\mathrm{H}_{3} \mathrm{PO}_{4}$ which was not washed completely during the activation .

\subsection{Thermogravimetric analysis of date fronds}

Figs(15-18). Show the percentage weight loss during TGA for palm dates frond. Two major weights lost that took place in this graph. The first range of decomposition happened at 40 to $132{ }^{\circ} \mathrm{C}$, which represent $6.1 \%$ weight lost. This is most possibly due to the moisture released by the sample during heating. The largest weight loss occurred at temperature range of about 132 to $400{ }^{\circ} \mathrm{C}$. This is due to decomposition of chemical . The high thermal stability.

\subsection{Statistical analysis}

Three separate studies were performed. Assays were run in triplicate for each material and at each time point and the data were analyzed using Student's t-test as described previously [43-45] and significance considered achieved at po(0:05). The surface area was determined according to langmuir, alpha-s , and BET method was shown in Figs(1-10) and tables(1-3).
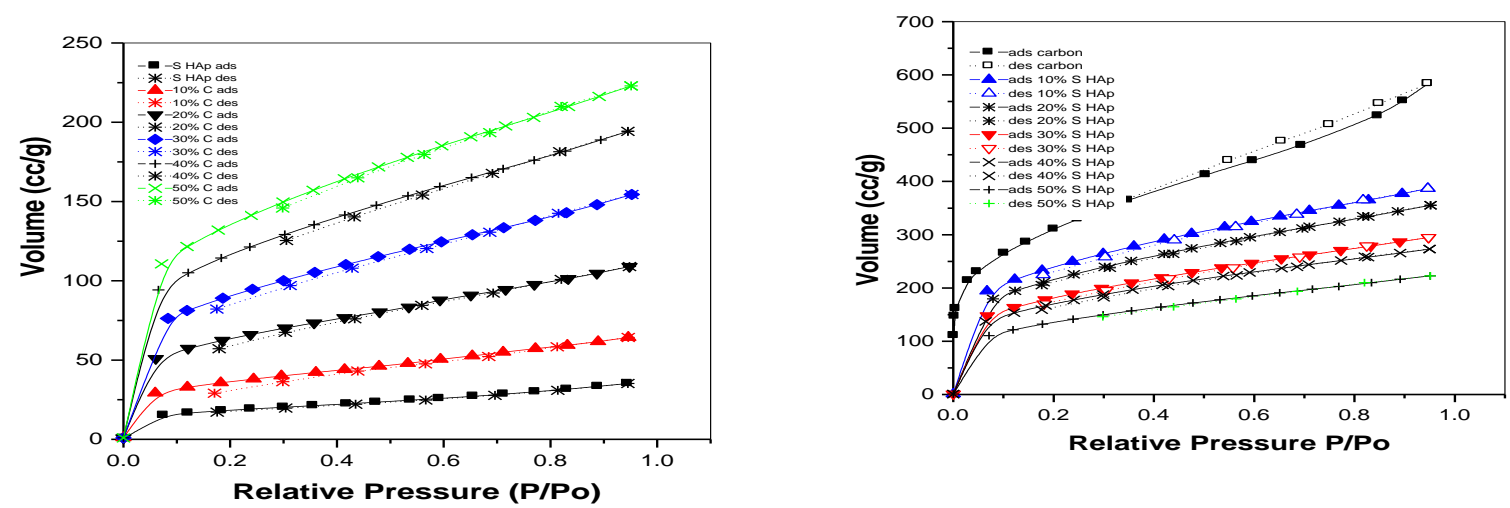

Fig (1):The adsorption isotherms of $\mathrm{N}_{2}$ at $77 \mathrm{~K}$ for the synthetic HAp mixed with different ratios (10-50\%) of ACs

Fig (2): The adsorption isotherms of $\mathrm{N}_{2}$ at $77 \mathrm{~K}$ for ACs mixed with different ratios (10-50\%) of the synthetic HAp 

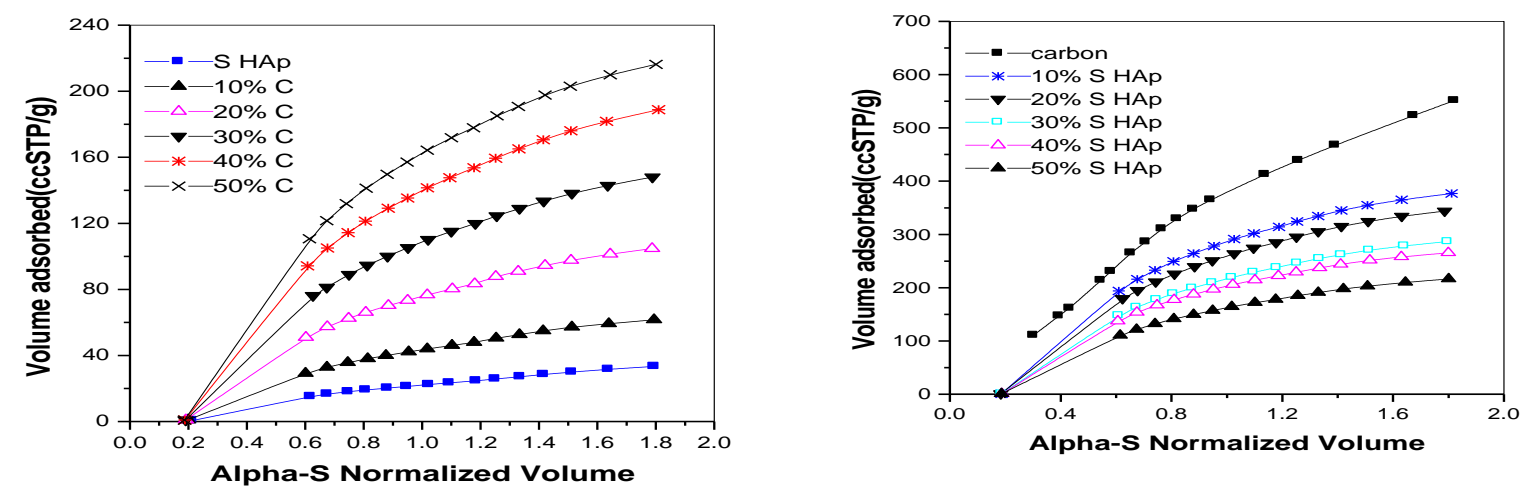

Fig.(3): The $\alpha_{s}$-plots for the synthetic HAp mixed with different ratios (10-50\%) of ACs.
Fig.(4): The $\alpha_{s}$-plots for ACs mixed with different ratios (10-50\%) of the synthetic HAp.
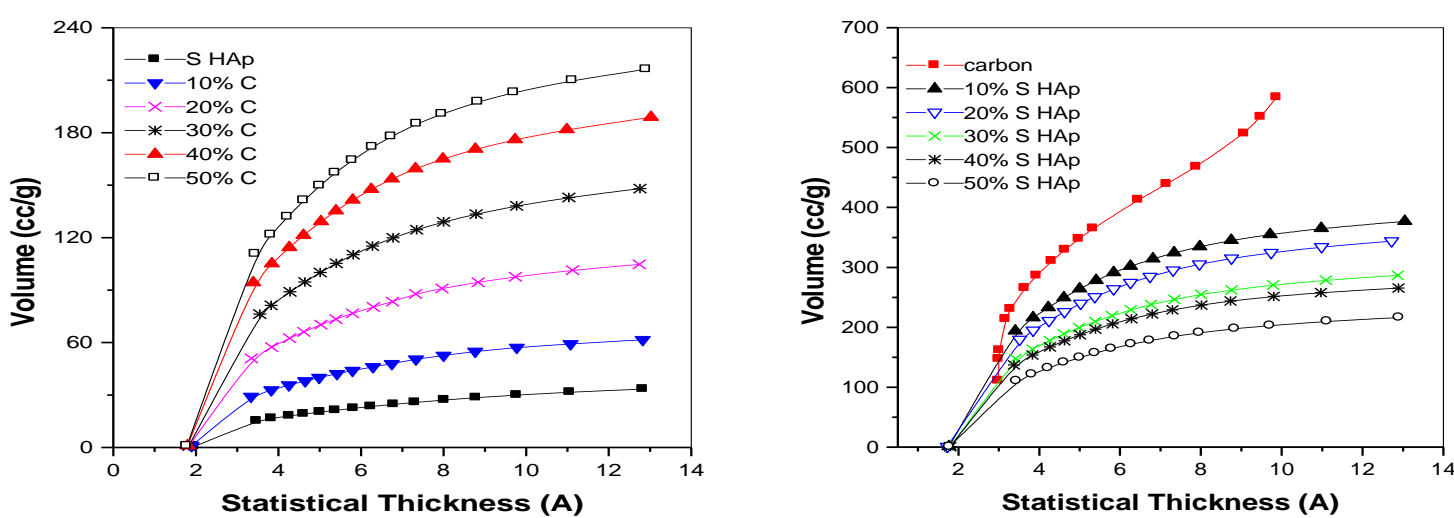

Fig.(5): The t-plots for synthetic HAp mixed with different ratios (10-50\%) of ACs.

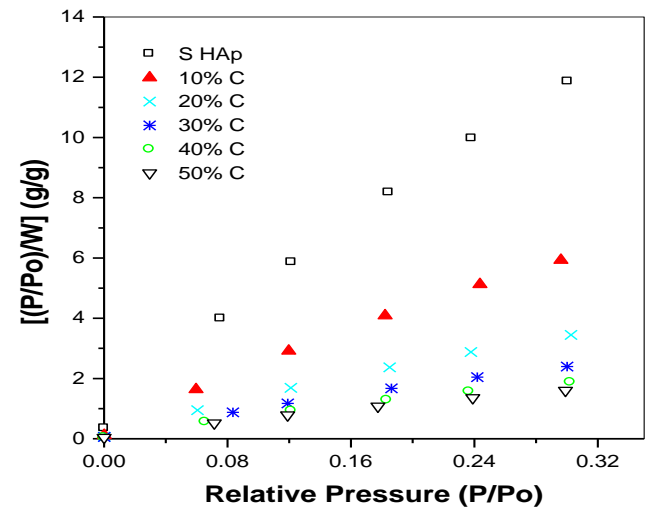

Fig.(7):Langmuir plots for synthetic HAp mixed with different ratios (10-50\%) of ACs.
Fig.(6): The t-plots for ACs mixed with different ratios (10-50\%) of synthetic HAp.

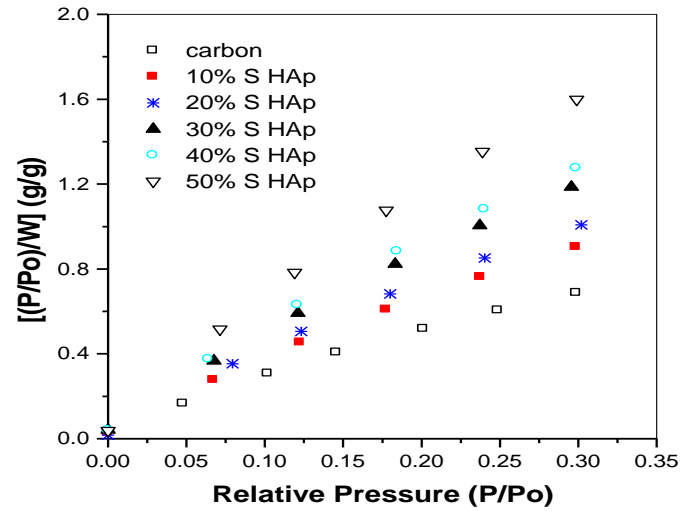

Fig.(8): Langmuir Plots for ACs mixed with different ratios (10-50\%) of synthetic HAp. 

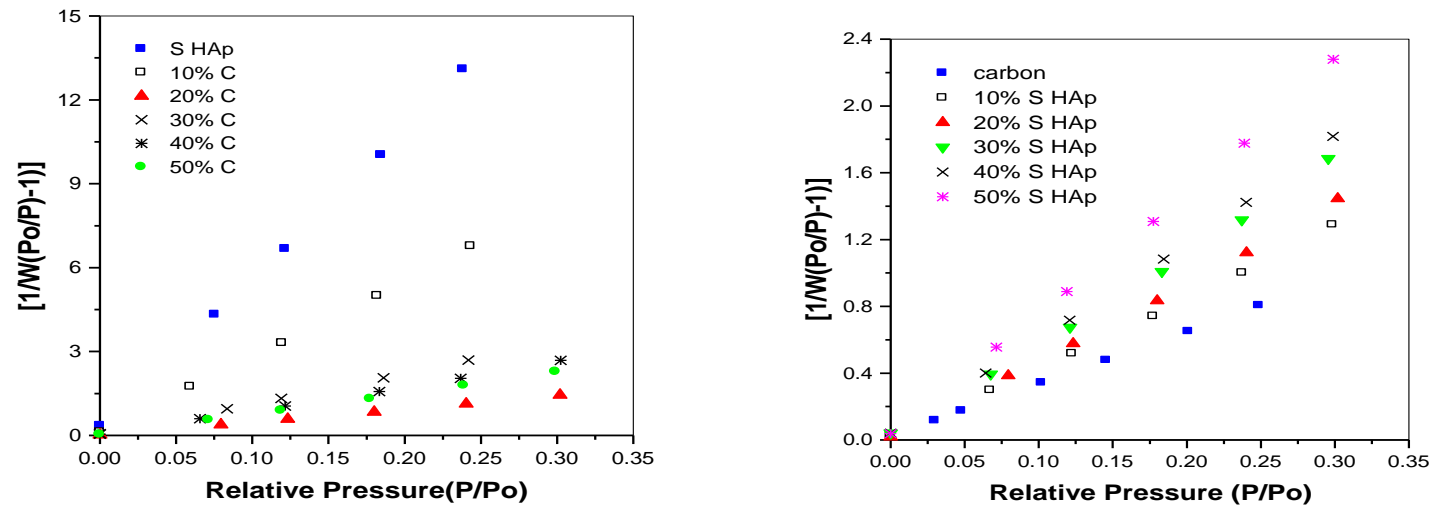

Fig.(9): BET- plots for synthetic HAp mixed With different ratios (10-50\%) of ACs.
Fig.(10): BET- plots for ACs, mixed with different ratios (10-50\%) of synthetic HAp.

Table 1.Surface characteristics of synthetic HAp mixed with different ratios (10-50\%) of ACs.

\begin{tabular}{|c|c|c|c|c|c|c|c|c|}
\hline $\begin{array}{c}\text { Type of S HAp - } \\
\text { C }\end{array}$ & $\begin{array}{l}\mathrm{S}_{\text {BET }} \\
\mathrm{m}^{2} / \mathrm{g}\end{array}$ & $\begin{array}{c}S_{t}^{\alpha} \\
\mathbf{m}^{2} / g\end{array}$ & $\begin{array}{c}S_{n}^{\alpha} \\
m^{2} / g\end{array}$ & $\begin{array}{c}V_{P} \\
\mathrm{ml} / \mathrm{g}\end{array}$ & $\begin{array}{l}\mathrm{V}_{\text {meso }} \\
\mathrm{ml} / \mathrm{g}\end{array}$ & $\begin{array}{l}\mathrm{V}_{\text {ou }} \\
\mathrm{ml} / \mathrm{g}\end{array}$ & $\begin{array}{l}\mathrm{V}_{\text {ot }} \\
\mathrm{ml} / \mathrm{g}\end{array}$ & $\begin{array}{c}\mathrm{V}_{\text {os }} \\
\mathrm{ml} / \mathrm{g}\end{array}$ \\
\hline S HAp only & 63.28 & 90.57 & 43.04 & 0.054 & 0.0435 & --- & 0.0105 & 0.0105 \\
\hline $10 \% \mathrm{C}$ & 127.67 & 166.08 & 72.09 & 0.099 & 0.0708 & --- & 0.0282 & 0.0282 \\
\hline $20 \% \mathrm{C}$ & 223.54 & 289.55 & 105.33 & 0.17 & 0.1077 & --- & 0.0623 & 0.0623 \\
\hline $30 \% \mathrm{C}$ & 319.05 & 437.84 & 157.00 & 0.24 & 0.1564 & --- & 0.0836 & 0.0836 \\
\hline $40 \% \mathrm{C}$ & 401.06 & 563.54 & 194.36 & 0.30 & 0.1882 & --- & 0.1118 & 0.1118 \\
\hline $50 \% \mathrm{C}$ & 466.76 & 655.32 & 216.95 & 0.34 & 0.205 & --- & 0.1350 & 0.1350 \\
\hline
\end{tabular}

Table 2. Surface characteristics of ACs, mixed with different ratios (10-50\%) of synthetic HAp.

\begin{tabular}{|c|c|c|c|c|c|c|c|c|}
\hline Type of C-SHAp & $\begin{array}{l}\mathbf{S}_{\text {BET }} \\
\mathrm{m}^{2} / \mathrm{g}\end{array}$ & $\begin{array}{c}\mathbf{S}^{\alpha}{ }_{t} \\
\mathbf{m}^{2} / g\end{array}$ & $\begin{array}{c}\mathbf{S}_{\mathrm{n}}^{\alpha} \\
\mathbf{m}^{2} / \mathrm{g}\end{array}$ & $\begin{array}{c}\mathrm{V}_{\mathbf{P}} \\
\mathrm{ml} / \mathrm{g}\end{array}$ & $\begin{array}{l}V_{\text {meso }} \\
\mathrm{ml} / \mathrm{g}\end{array}$ & $\begin{array}{l}\mathrm{V}_{\text {ou }} \\
\mathrm{ml} / \mathrm{g}\end{array}$ & $\begin{array}{c}\mathrm{V}_{\text {ot }} \\
\mathrm{ml} / \mathrm{g}\end{array}$ & $\begin{array}{c}V_{\text {os }} \\
\mathrm{ml} / \mathrm{g}\end{array}$ \\
\hline Carbon only & 1104.65 & 1220.01 & 612.07 & 0.903 & 0.648 & -- & 0.255 & 0.255 \\
\hline $10 \%$ S HAp & 827.67 & 1099.88 & 350.39 & 0.598 & 0.339 & --. & 0.259 & 0.259 \\
\hline $20 \%$ S HAp & 741.69 & 989.23 & 332.14 & 0.550 & 0.323 & $-\cdots$ & 0.227 & 0.227 \\
\hline 30\% S HAp & 628.50 & 835.67 & 270.90 & 0.456 & 0.263 & $-\cdots$ & 0.193 & 0.193 \\
\hline 40\% S HAp & 587.43 & 780.21 & 255.23 & 0.423 & 0.245 & $-\cdots$ & 0.178 & 0.178 \\
\hline $50 \%$ S HAp & 466.76 & 655.32 & 216.95 & 0.34 & 0.205 & --- & 0.1350 & 0.135 \\
\hline
\end{tabular}

Table 3. Surface characteristics of ACs, mixed with different ratios of the synthetic HAp.

\begin{tabular}{|c|c|c|}
\hline $\begin{array}{c}\text { Type of } \\
\text { S HAp }\end{array}$ & $\begin{array}{c}\text { Langmuir surface area } \\
\mathrm{S}_{\mathrm{L}}\left(\mathrm{m}^{2} / \mathrm{g}\right)\end{array}$ & $\begin{array}{c}\text { Average pore radius } \\
\text { r }(\mathbf{A})\end{array}$ \\
\hline S HAp only & 91.67 & 17.06 \\
\hline $10 \% \mathrm{C}$ & 179.06 & 15.51 \\
\hline $20 \% \mathrm{C}$ & 314.18 & 15.21 \\
\hline $30 \% \mathrm{C}$ & 451.58 & 15.04 \\
\hline $40 \% \mathrm{C}$ & 609.38 & 14.96 \\
\hline $50 \% \mathrm{C}$ & 709.19 & 14.56 \\
\hline Carbon only & 1688.42 & 16.35 \\
\hline $10 \%$ S HAp & 1260.09 & 14.45 \\
\hline $20 \%$ S HAp & 1129.40 & 14.83 \\
\hline $30 \%$ S HAp & 950.53 & 14.51 \\
\hline $40 \%$ S HAp & $\mathbf{8 8 9 . 7 8}$ & 14.40 \\
\hline $50 \%$ S HAp & 709.19 & 14.56 \\
\hline
\end{tabular}




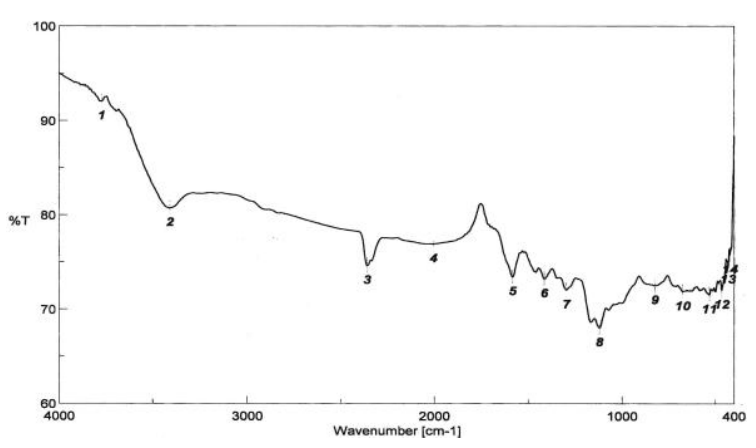

Fig.11. FTIR-Spectra of activated carbon obtained from date frond DF by chemical activation.

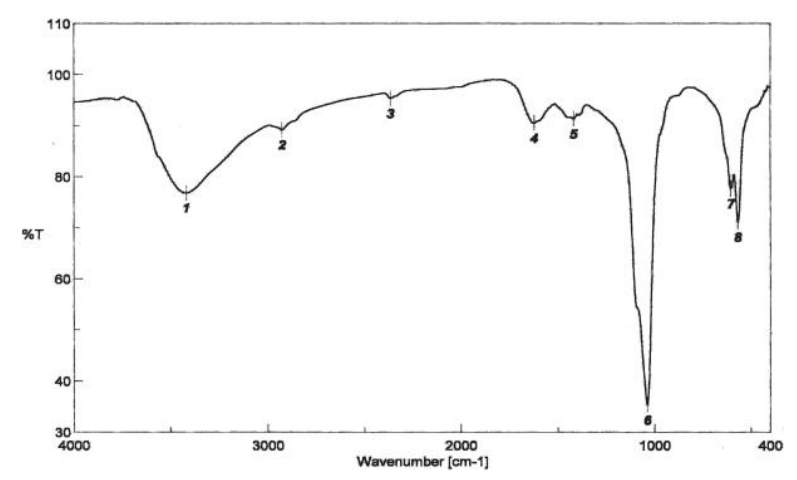

Fig.13. FTIR-Spectra for the synthetic Hap mixed with $40 \%$ DF carbon.

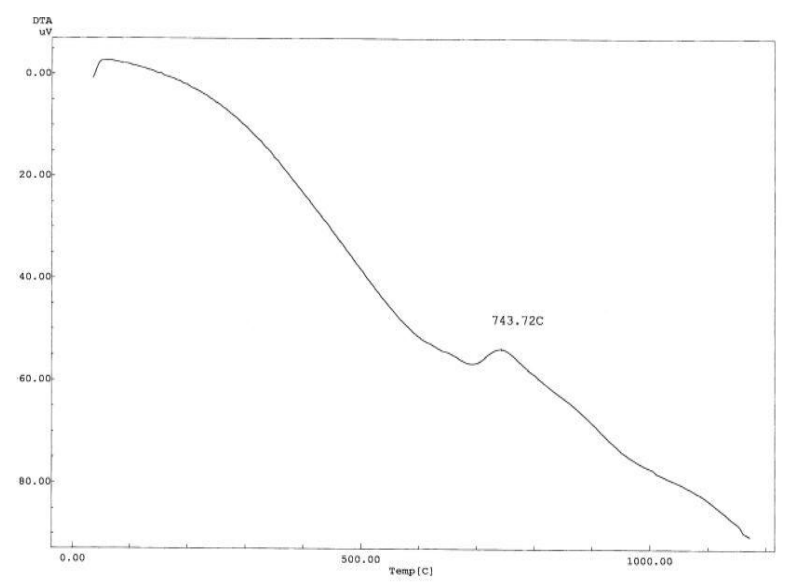

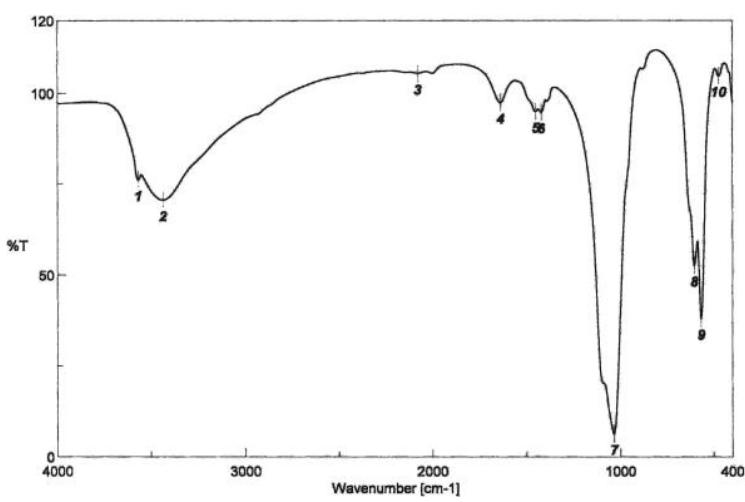

Fig.12. FTIR-Spectra for the synthetic HAp

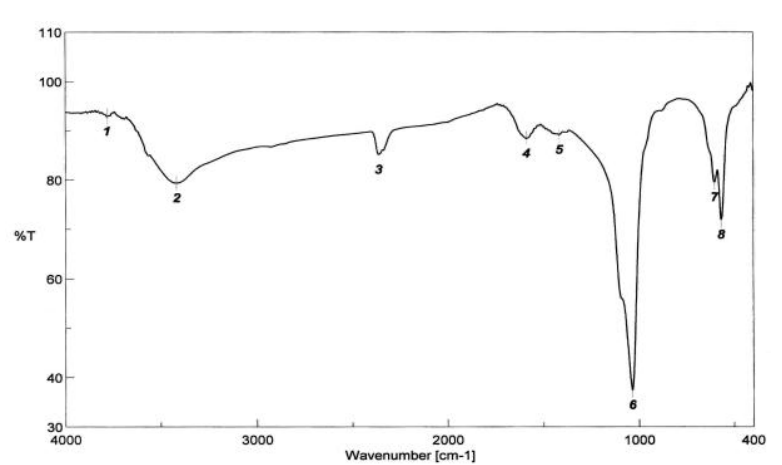

Fig.14. FTIR-Spectra for DF activated carbon mixed with $50 \%$ synthetic HAp. 


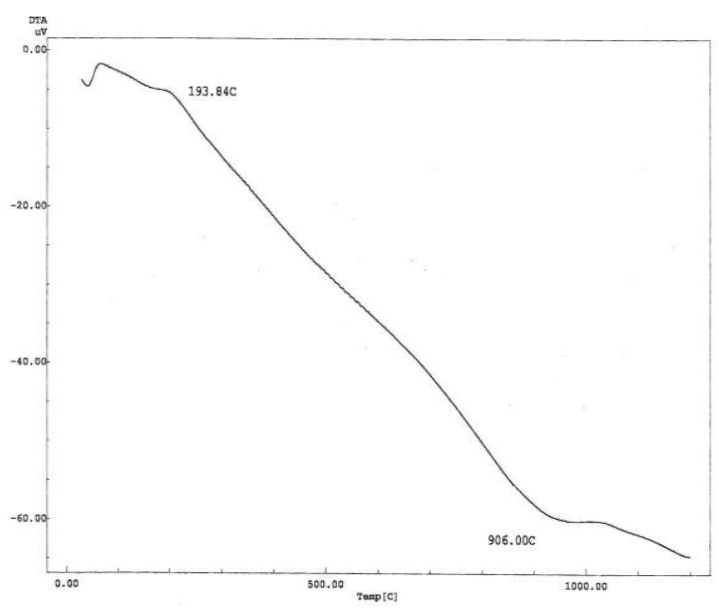

Fig (15): DTA- Spectra of activated carbon obtained from date frond DF by chemical activation.

Fig (16): DTA-Spectra for the synthetic HAp.

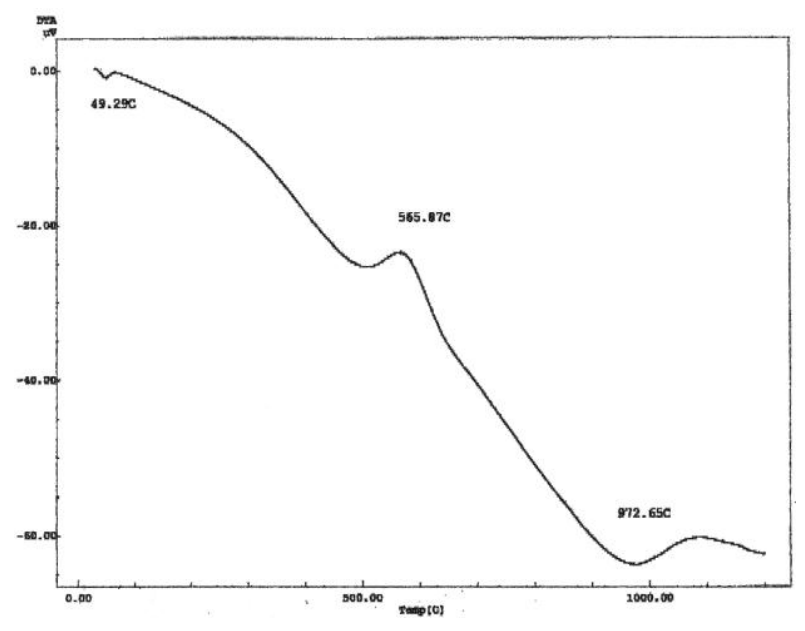

Fig (17): DTA-Spectra for DF activated carbon mixed with $40 \%$ synthetic HAp

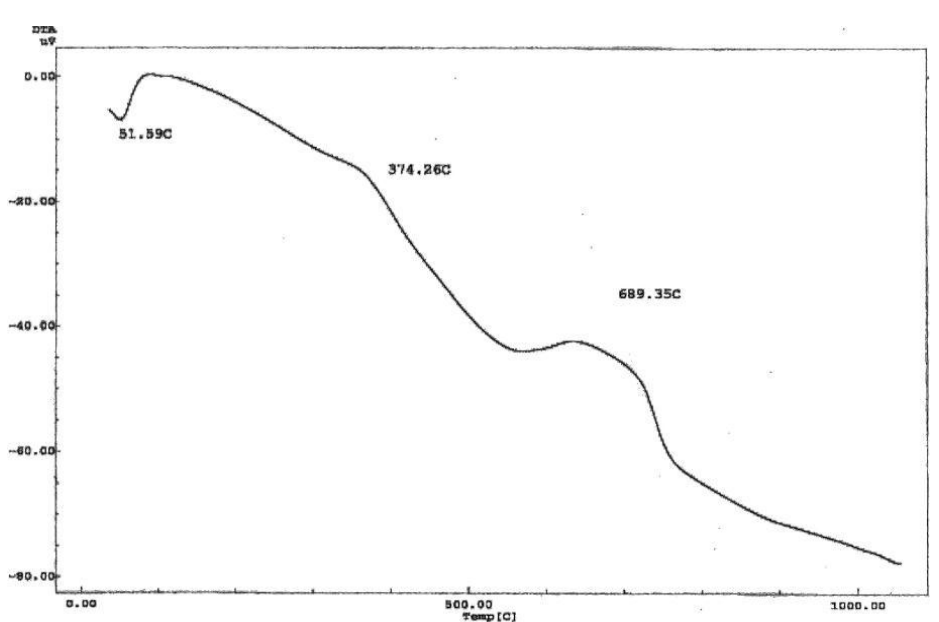

Fig (18): DTA-Spectra for DF activated carbon mixed with $50 \%$ synthetic HAp. 


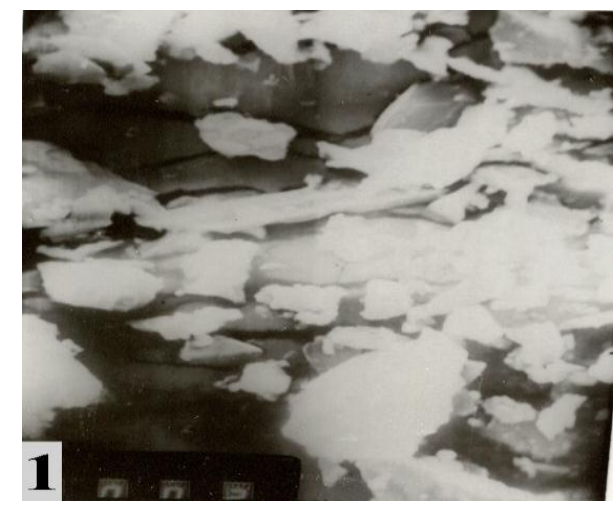

Fig.19. SEM-plot for activated carbon obtained from DF by chemical treatment.

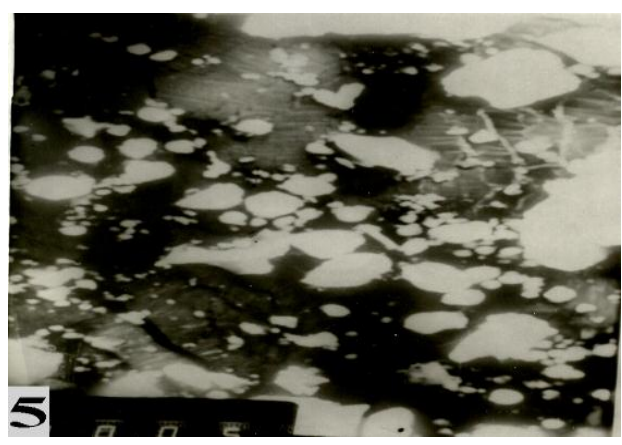

Fig.21. SEM-plot for synthetic synthetic HAp mixed with $40 \%$ of DF carbon.

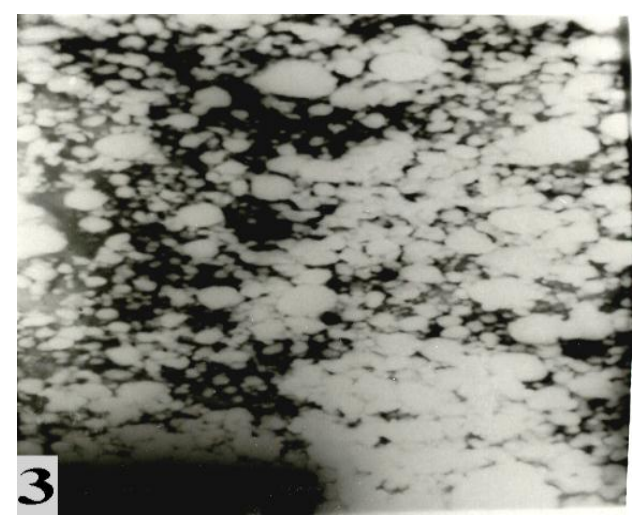

Fig.20. SEM-plot for synthetic HAp.

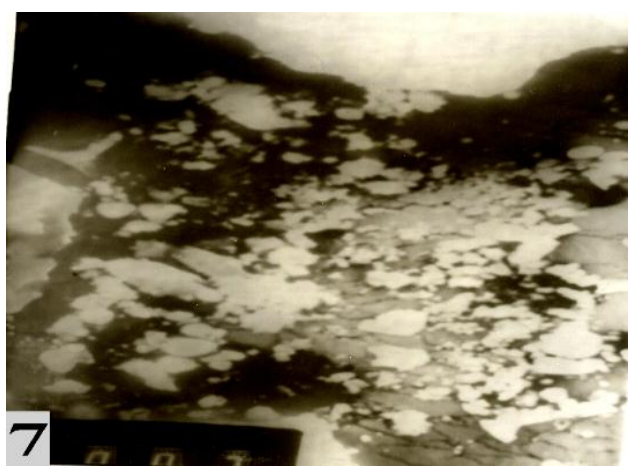

Fig.22. SEM-plot for DF carbon mixed with $40 \%$ of synthetic HAp.

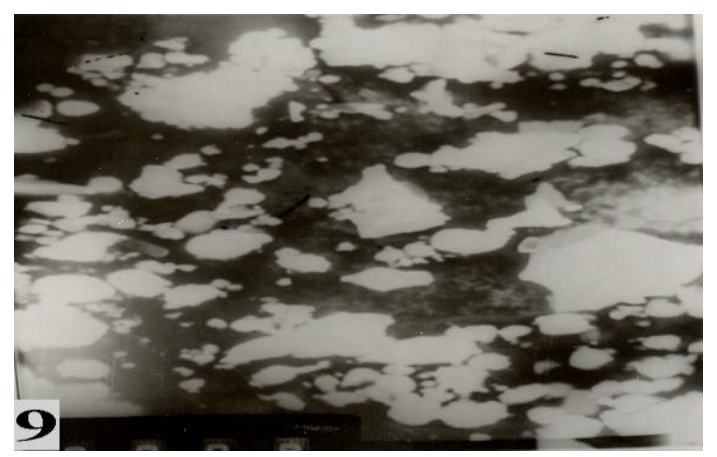

Fig.23. SEM-plot for DF carbon mixed with $50 \%$ of synthetic HAp.

\section{Conclusion}

The nannoparticle apatite -carbon materials was prepared successfully can be used for medical applications.

\section{References}

[1] B.R. Constantz, I.C. Ison, M.T. Fulmer, et al., Science 267 (1995) 1796.

[2] M. Toriyama, et al., J. Eur. Ceram. Soc. 16 (1996) 429-436.

[3] C. Lavernia, J.M. Schoenung, Bull. Amer. Ceram. Soc. Ceram. Bull. 70 (1991) 95.

[4] V. Sergo, O. Sbaizero, D.R. Clarke, Biomaterials 18 (1997) 477.

[5] I.F. Vasconcelos, et al., J. Mater. Sci. Lett. 18 (1999) 1871.

[6] I.F. Vasconcelos, J. Mater. Sci. 36 (2001) 587.

[7] C. Chenglin, et al., Mater. Sci. Eng. A 271 (1999) 95-100.

[8] J.-M. Wu, et al., J. Mater. Sci. 23 (1998) 3771.

[9] R. Halouani, et al., J. Mater. Sci. Mater. Med. 5 (1994) 563.

[10] T.K. Chaki, et al., J. Mater. Sci. Mater. Med. 5 (1994) 533. 
[11] P.G.Galliano,J.M. Porto Lopéz, J. Mater. Sci. Mater. Med. 6 (1996)353-359.

[12] H. Kim, et al., J. Amer. Ceram. Soc. 85 (6) (2002) 1634-1636.

[13] X. Nie, A. Leyland, A. Matthews, Surf. Coat. Technol. 125 (2000)407-414.

[14] M.J. Yaszemsk, et al., Biomaterials 17 (1996) 175.

[15] H.S. Liu, et al., Ceram. Internat. 23 (1997) 19.

[16] G.F. Fernandes, et al., Quim. Nova 23 (2000) 441.

[17] G. Heimke, Angew. Chem. 101 (1989) 111.

[18] L.L. Hench, J. Amer. Ceram. Soc. 74 (1991) 1487.

[19] M.R. Bet, et al., Quim. Nova 20 (1997) 475.

[20] R.S. de Figueiredo, A. Messai, A.C. Hernandes, A.S.B. Sombra, J. Mater. Sci. Lett. 17 (1998) 449.

[21] Hench LL. Bioceramics: from concept to clinic. J Am Ceram Soc 1991;74:1485-510.

[22] Hutmacher DW. Polymeric scaffolds in tissue engineering bone and cartilage. Biomaterials 2000;21:2529-43.

[23] Niinomi M. Fatigue performance and cyto-toxicity of low rigidity titanium alloy, Ti-29Nb-13Ta-4.6Zr. Biomaterials 2003;24:2673-8263.

[24] Long M, Rack HJ. Titanium alloys in total joint replacement - amaterials science perspective. Biomaterials 1998;19:1621-39.

[25] Brunette DM, Tengvall P, Textor M, Thomsen P. Titanium in medicine. Heidelberg: Springer-Verlag; 2001.

[26] Steinemann SG. In: Winter GD, Leray JL, Groot de K, editors. Evaluation of biomaterials. New York: Wiley; 1980.

[27] Inoue A. Stabilization of metallic supercooled liquid and bulk amorphous alloys. Acta Mater 2000;48:279-306.

[28] Wen CE, Yamada Y, Hodgson PD. Fabrication of novel alloy foams for biomedical applications. Mater Forum 2005;29:274-8.

[29] Samuneva B, Kozhukharov V, Trapalis Ch, Kranold R. Sol-gel processing of titanium-containing thin coatings. J Mater Sci 1993;28: 2353-560.

[30] Kim HW, Koh YH, Li LH, Lee S, Ee H. Hydroxyapatite coating on titanium substrate with titania buffer layer processed by sol-gel method. Biomaterials 2004;25:2533-8.

[31] Niinomi M,Akahori T,Takeuchi T,Katsura S.Dental precision casting of $\mathrm{Ti}-29 \mathrm{Nb}-13 \mathrm{Ta}-4.6 \mathrm{Zr}$ using calcia mold. Mater Sci Forum 2005;475-479:2303-8.

[32] Yu JG, Zhao XJ, Zhao QN. Effect of surface structure on photocatalytic activity of TiO2 thin films prepared by sol-gel method. Thin Solid Films 2000;379:7-14.

[33] Harizanov O, Harizanova A. Development and investigation of sol-gel solutions for the formation of TiO2 coatings. Sol Energy Mater Sol Cells 2000;63:185-95.

[34] Montenero A, Gnappi G, Ferrari F, Cesari M, Salvioli E, Mattogno L, et al. Sol-gel derived hydroxyapatite coatings on titanium substrate. J Mater Sci 1000;35:2791-7.

[35] Hsieh MF, Perng LH, Chin TS. Hydroxyapatite coating on Ti6Al4V alloy using a sol-gel derived precursor. Mater Chem Phys 2002;74: 245-50.

[36] Ishizawa $\mathrm{H}$, Ogino $\mathrm{M}$. Hydrothermal precipitation of hydroxyapatite on anodic titanium oxide films containing Ca and P. J Mater Sci 1999;34:5893-8.

[37] Berndt CC, Haddad GN, Farmer AJD, Gross KA. Spraying for bioceramic applications - a review. Mater Forum 1990;14:161-73.

[38] Cotell CM, Chrisey DB, Grabowski KS, Sprague JA. Pulsed laser deposition of hydroxyapatite thin films on Ti-6Al-4V. J ApplBiomater 1992;3:87-93.

[39] Zhitomirsky I, Or LG. Electrophoretic deposition of hydroxyapatite.J Mater Sci Mater Med 1997;8:213-9.

[40] Liu DM, Yang Q, Troczynski T.Sol-gel hydroxyapatite coating on stainless steel substrates. Biomaterials 2002;23:691-8.

[41] Wen CE, Yamada Y, Shimojima K, Chino Y, Hosokawa H, Mabuchi M. J Mater Res 2002;17:2633-9.

[42] Gu YW, Khor KA, Cheang P. In vitro studies of plasma-sprayed hydroxyapatite/Ti-6Al-4V composite coatings in simulated body fluid (SBF). Biomaterials 2003;24:1603-11.

[43] Cle`ries L, Ferna'ndez-Pradas JM, Morenza JL. Behavior in simu lated body fluid of calcium phosphate coatings obtained by laser ablation. Biomaterials 2000;21:1861-5.

[44] Koike M, Fujii H. The corrosion resistance of pure titanium in organic acids. Biomaterials 2001;22:2931-6.

[45] Gross KA, Berndt CC. In vitro testing of plasma-sprayed hydroxyapatite coati ngs. J Mater Sci Mater Med 1994;5:219-24. 